\title{
Editorial: REGION - the online open-access journal of ERSA
}

\author{
Julia Koschinsky ${ }^{1}$, Sierdjan Koster ${ }^{2}$, Roberto Patuelli ${ }^{3}$, Vicente Royuela ${ }^{4}$, \\ Vassilis Tselios ${ }^{5}$ \\ ${ }^{1}$ Arizona State University, Tempe, AZ, USA (email: julia.koschinsky@asu.edu) \\ ${ }^{2}$ University of Groningen, Groningen, The Netherlands (email: sierdjan.koster@rug.nl) \\ ${ }^{3}$ University of Bologna, Rimini, Italy (email: roberto.patuelli@unibo.it) \\ ${ }^{4}$ University of Barcelona, Barcelona, Spain (email: vroyuela@ub.edu) \\ ${ }^{5}$ University of Southampton, Southampton, United Kingdom (email: v.tselios@soton.ac.uk)
}

Received: 9 April 2014/Accepted: 9 April 2014

\begin{abstract}
This editorial launches REGION, the new online and open-access journal of ERSA. REGION aims to be a high-quality academic journal in the field of regional science. To its contributors, it offers a solid peer-review process and immediate publication upon acceptance. Also, it will be a flexible outlet, not bound by traditional journal formats or strict page limits. To its readers, the journal offers high-standard publications on current issues in regional science that are easily accessible through its website. Both submitting to the journal and accessing the contributions are free of charge to everyone.
\end{abstract}

\section{Why a new journal?}

The journal is launched at a time when the European Regional Science Association and regional science in general are in good shape. The year 2014 marks 60 years since the founding of the Regional Sciences Association by Walter Isard. ERSA followed soon after in 1960, and had its first conference in Den Haag, the Netherlands. In the following fifty to sixty years, there have been ups and downs. In the 1990s, several authors painted a grim picture of regional science, suggesting it was losing its relevance (Isserman, 1993, 1995; Bailly and Coffey, 1994). Since then, the sentiment has become more upbeat, with Quigley (2001) observing a renaissance in regional science. Certainly, analyses of regional dynamics have gained currency in policy debates with the increased focus, as in the EU, on place-based development. Moreover, regional science has gained momentum in academia, exemplified by the Nobel Prize awarded to Paul Krugman, including for his work on geography and trade. The increased number of articles published in journals such as Papers in Regional Science and Journal of Regional Science, in combination with their increasing impact scores, may also be seen as tokens of the relevance and quality of the field.

ERSA is also in good shape as an organization. Today it has eighteen sections across Europe with new ones still being established. In addition, its annual conference sees a steadily increasing attendance, recently attracting over 1,000 participants. Another positive development has been the increased attention given to young scholars at the annual conferences. The Young Scientist Sessions are well-attended, growing in size, and attracting high-quality contributions from all over Europe and beyond. 
REGION aims to accommodate the increasing output of high-quality research in regional science. The journal provides an easily accessible platform for all regional science researchers, including those that may have difficulties accessing the existing subscriptionbased journals. This includes researchers from emerging countries that may lack a research infrastructure providing such access, but also young researchers, including undergraduate students, finding their way into regional science.

The journal is launched at a time when the methods available to disseminate academic output are changing dramatically. The Internet and the digitization of information have made it easier to publish and to a wider audience. The increasing ease of publication and access to academic output has materialized in many ways: virtually all relevant journals are available in digital form, purely online journals have been launched, and researchers start blogs, Twitter feeds, YouTube channels and so on. These trends run in parallel with an institutional movement towards open access, exemplified by the "Berlin declaration on Open Access to knowledge in the sciences and humanities" ${ }^{1}$ which calls for free access to all scientific knowledge. This movement is further fuelled by research-funding organizations increasingly pushing for open-access publication of research output. The European Commission, for example, announced that all publications emanating from its Horizon 2020 funding programme must be open access. Several national funding bodies have similar requirements. Despite this push for open access publishing, there remains a dearth of reputable open-access journals, and open-access publication in reputable subscription-based journals is often costly. REGION aims to contribute to the reputation and acceptance of open-access publishing in regional science and, by being supported by a large and reputable organization, can draw from its network to ensure quality peer review. As such, REGION will offer a free yet reliably high-quality research outlet circumventing some of the current obstacles to open-access publication.

Research practices are also changing as a result of technical advances and digitization. Large micro-level register-based datasets are increasingly available for research, as well as geo-referenced data based on information derived from communication devices and social network applications (locations of Twitter feeds and mobile phone data, for example). These developments pose new challenges to the processing, analysis and visualization of the data. Register-based datasets, for example, tend to have restricted access and this compromises the possibility of reproducing results. Another case in point is the increasingly common open-source data collection based on the GPS locations of communication devices. Although inclusive and fully transparent, the resulting data and the collection process tend to be complex. Both these examples reflect an increasing need for debate concerning data collection, data quality and the use of data in regional science.

Social sciences, including regional science, have not been at the forefront in the developments outlined above. REGION is a response that aims to provide a platform for presenting and discussing current developments in data collection, analysis and visualization. Publishing traditional articles may not be the most appropriate form for such discussions. Therefore, REGION includes a distinct "Resources" section that allows more flexible formats to be used in publishing research output related to data.

\section{How does REGION work?}

REGION aims to be a high quality open-access journal in regional science in its broadest sense. As such, we welcome both theoretical and empirical contributions. Further, although REGION is organizationally tied to ERSA, we encourage scholars from around the globe to contribute. There is no geographical constraint on the topics addressed. Contributions addressing issues beyond Europe are as equally welcome as contributions with a European focus.

REGION combines the scientific rigour offered by traditional journals with new possibilities offered by its online-only format. In other words, each contribution will go through the usual double-blind peer-review process. The journal will call on the network of reviewers that is available through the ERSA organization and through the members of its editorial board. They form the vanguard of the journal's reviewers. The online

\footnotetext{
${ }^{1}$ See http://openaccess.mpg.de/286432/Berlin-Declaration.
} 
nature of REGION allows it to be flexible in the way that contributions are organized and presented. This is reflected in the main sections of the journal: Original Articles, the Resources section and the Young Scholars' Letters. Original Articles will follow conventional formats in which new research results are presented and the articles will be evaluated accordingly. The fact that publication is not bound by a page limit allows for flexibility in evaluating the length of the submissions related to the content.

REGION has a dedicated section for researchers in the early phases of their careers: the Young Scholars' Letters. Contributions to this letters section are typically shorter (around 3,000 words) and report theoretical or empirical studies carried out by early-stage researchers, such as Master and PhD students or recent graduates. Such contributions will still be peer reviewed and we will actively engage early-career scholars in the review process.

Finally, REGION includes a Resources section which most clearly exploits the possibilities of online publication. This section offers an outlet for academic output related to data and information. Contributions should include a title, author(s), and a short summary that can be cited. After this the format is freer, authors can include presentations of datasets, visualizations of spatial data and results, descriptions of newly-constructed open-source datasets and code to address common data issues or to implement new econometric techniques. Moreover, multimedia content such as screenshots of data sources, software demos, review videos and featured graphics can be included to supplement text.

\section{To conclude}

Regional science continues to evolve and grow and the ways in which academic knowledge is produced and presented are similarly evolving. This context offers space for a new online and open-access journal in regional science. We are thus proud to present REGION, and we are confident that it will combine the high-quality standards of existing academic journals in regional science with new possibilities offered by its format and open access for years to come.

\section{References}

Bailly, AS and Coffey WJ (1994) Regional science in crisis: a plea for a more open and relevant approach. Papers in Regional Science 73: 3-14

Isserman, AM (1993) Lost in space? on the history, status, and future of regional science. The Review of Regional Studies 23: 1-50

Isserman, AM (1995) The history, status and future of regional science: an American perspective. International Regional Science Review 17: 249-296

Quigley, JM (2001) The renaissance in regional research. The Annals of Regional Science 35: 167-178 